\title{
Personal Digital Assistants (PDAs) in Pediatrics \& Paediatric Critical Care Websites
}

\author{
Vidhyashankar $\mathbf{C}^{1}$ \\ ${ }^{1}$ Dr. C Vidya Shankar, Specialist Pediatrician, Apollo Clinic, Doha, Qatar \\ Address for Correspondence: vidyashankarc@hotmail.com
}

\section{PDA's for Paediatricians}

Thousands of years ago in Mesopotamia, doctors used to refer to prescribing and treatment guidelines etched on palm-sized clay tablets. Today, almost half of US doctors use another kind of handheld device called a personal digital assistant, or PDA(also called a handheld)

This stands for Personal Digital Assistant and these are now really powerful palm sized computers which doctors may find invaluable in their daily lives.

\section{Medical Uses of PDA's}

Look up information of various diseases.

Drug reference.

Access Internet

Run medical diagnostic programs.

Run medical software.

Use as an image library.

Take photos and transmit images for use in Telemedicine.

Read textbooks and medical journals

\section{How to buy a PDA?}

There are a large number of PDA's available in the market, most of then have equivalent features. The following points need consideration - Price, ease of use, available software and additional features.

The additional features are very important - Blue tooth and Wi-Fi, camera and mobile phone; music, keyboard etc are some of the features that are now integrated into the PDA. Blue tooth is a way to wirelessly connect with other portable devices. Common examples are the wireless earpieces for cell phones or the way that cars can connect to cell phones.

Wi-fi is a wireless Internet connection, like the kind offered at coffee shops and airports. It is typically very fast. More and more hospitals use this technology as well. This technology is helpful if you have Wi-Fi capability at home or at work. Also the number of airports with Wi-Fi access is greatly increasing. Therefore you can surf the web, check email while waiting on your flight.

Most PDA's are similarly priced, but it is preferable to buy PDA's using the Palm or windows operating system. There are now two leading operating systems (OS) in the market. The dominant one commanding the largest market share is Palm OS. PDAs running Palm OS include Palm, Handspring, Handera (formerly TRGPro) and Sony Clio. Another one is Microsoft's PocketPC platform. The most popular PocketPC powered PDA is Compaq's iPaq pocketPC, Casio and HP. This list is not complete as you may get more PDA's using the same operating systems.

\section{Putting Medical Software on these PDAs}

Once you have bought the PDDA you need to put software in it. Just like buying software for your computer you can buy software for your PDA. Usually the first reference that the adventuresome medical PDA user obtains is a drug reference. Most will give dosing, indications, dosage forms, and more. Some of the references are free. Most of the Palm software is purchased over the web.

Most medical books, including all the popular pediatric books and journals have their PDA version. A large collection of information on PDA's for Pediatricians is listed in these websites -

Pediatrics on Hand - http://www.dcchildrens.com/pdas/ home.aspx

Medical Handheld Computing - http://www.drsref.com. au/handhelds.html

Unbound Medicine - www.unboundmedicine.com

Diagnosarus - http://books.mcgraw-hill.com/medical/ diagnosaurus/index.html

This is free medical diagnostic software for the PDA.

MEDSPDA - www.medspda.com

This site contains a collection of software for Pediatrics and other specialities.

NETDOC - www.netdoc.com

Contains free software for PDA users.

\section{Neonatology on the Web}

Pediatrics/Neonatal Intensive Care websites -

The internet is an important source of medical education. Information sources on Pediatric/neonatal intensive care are now available at the click of a mouse. Some information sources are listed below.

\section{Pediatric Critical Care Course}

http://www.sccm.org/SCCM/Specialties/Pediatrics/ PICU+Course/

The Pediatric Resident Education Committee, a subcommittee of the Pediatric Section of the Society of Critical Care Medicine (SCCM), has developed this site. The site contains educational material in the form of Adobe PDF presentations on topics that form a core curriculum for housestaff (medical students and residents) in the area of Pediatric 
Critical Care Medicine. These presentations have been authored by members of the Resident Education Committee and are available for download to your computer/server.

\section{Pediatric critical care medicine}

www.pedsccm.org

PedsCCM is a collaborative, independent, information resource and communication tool for professionals caring for critically ill and injured infants and children. The website contains articles, lectures, literature reviews, case reports and practical materials, e.g., clinical pathways. The multidisciplinary and practical resource for Pediatric Critical Care on the Internet Peer reviewed original content integrated with links to selected web resources.

\section{ISABEL -}

http://www.isabel.org.uk/

Isabel is an award-winning, clinical decision support system designed to enhance the quality of diagnosis decision making. Its unique feature is a diagnosis reminder system. For a given set of clinical features Isabel instantly provides a checklist of likely diagnoses, related diagnoses and causative drugs.

\section{Supermagnus}

http:/www.supermagnus.com/med/drips/

This online calculator creates drip sheets for pediatric patients and may be useful for settings such as pediatric intensive care units (PICUs), ambulances, etc. Use of the sheets should be self-explanatory to those who may have a need for them. They were intended to be printed out and taped to the patient's bedside in the event of an emergency.

\section{NICU TOOLS -}

http://www.nicutools.org/

This Website contains a collection of calculators for use in neonatology including, IV fluids, glucose, ventilation and nutrition.

\section{Virtual Pediatric Intinsive Care Unit -}

http://www.picu.net/

This is a common information space for the international community of care givers providing critical care for children. The website contains pediatric software, pediatric education, and a collection of online education materials on pediatric intensive care.

NICU web -

http://depts.washington.edu/nicuweb/NICU-WEB

NICU web is an on-line reference source authored by the Division of Neonatology at the University of Washington for pediatric housestaff and for primary care providers to support the divisional teaching, patient care and research mission. The future development of the site is being guided by the Pediatric Residency curriculum for neonatology and newborn medicine. The website contains materials on neonatal conditions, procedures and other neonatal resources. 